\title{
O Unheimliche contemporâneo: Gonçalo M. Tavares e a epopeia
}

\section{The Contemporary Unheimliche: Gonçalo M. Tavares and the Epic Poem}

Evelyn Blaut Fernandes [eveblaut@yahoo.com.br]

Universidade Federal do Rio de Janeiro, Brasil

\begin{abstract}
RESUMO
Partindo do reconhecimento de que a obra de Luís de Camões consiste na pedra angular do cânone literário português, este artigo reflete sobre a relação do Poeta quinhentista com a produção contemporânea da literatura portuguesa cuja leitura aponta como Os Lusíadas simbolizam a própria memória de uma cultura, ampliando sua notória influência na epopeia de Gonçalo M. Tavares. Esta influência é notável desde a repetição da estrutura épica camoniana. Porém, Uma viagem à Índia, ao mesmo tempo em que problematiza as versões épicas através do deslocamento de Bloom em contexto de perseguição e fuga, avança na leitura dialética das contradições do amor. Em forma de colagem, este texto procura acompanhar o itinerário desta (contra)epopeia e elaborar propostas de interpretação para esta personagem: (anti)herói, fugitivo, exilado, flâneur ou Unheimliche contemporâneo?
\end{abstract}

\section{Palavras-Chave}

Gonçalo M. Tavares; ler Camões no século xxi; Unheimliche.

\section{Abstract}

Based on the recognition that the Luís de Camões' work is the cornerstone of Portuguese literary canon, this article reflects on the $16^{\text {th }}$ century Poet's relationship with the contemporary production of Portuguese literature whose reading points out how The Lusiads symbolize the very memory of a culture, expanding its notorious influence in the epic by Gonçalo M. Tavares, which is remarkable since the repetition of the Camonian epic structure. While questioning the epic versions through the displacement of Bloom's character in the context of persecution and escape, A trip to India moves forward on the dialectic interpretation of the contradictions of love. In the manner of a collage, this text seeks to follow the itinerary of this (anti)epic and elaborate proposals of interpretation for its character: (anti)hero, runaway, outcast, flâneur or contemporary Unheimliche?

\section{KEYWORDS}

Gonçalo M. Tavares; reading Camões in the $21^{\text {st }}$ century; Unheimliche.

RECEBIDO 2019-04-20; ACEITE 2019-06-30

Este artigo é parte integrante do Projeto O desejo de esquecer: Gonçalo M. Tavares e a epopeia desenvolvido no Programa de Pós-Graduação de Letras Vernáculas da Universidade Federal do Rio de Janeiro e conta com uma bolsa de Pós-Doutorado Nota 10 da Fundação de Amparo à Pesquisa do Estado do Rio de Janeiro - FAPERJ. 


\section{1. "as portas da Índia estavam fora de alcance”}

Transcrevo, na íntegra, uma das epígrafes do prefácio de Eduardo Lourenço para Uma viagem à Índia:

Já no tempo de Alexandre as portas da Índia estavam fora de alcance, mas, ao menos, o gládio do rei mostrava a sua direcção. Hoje, as famosas portas estão mais longe e mais inacessíveis; mas ninguém mostra a direcção; muita gente brande gládios mas o olhar que pretende segui-los perde-os de vista. Franz Kafka, «O Novo Advogado», em A metamorfose

Se as portas da Índia já não estão mais fora de alcance e já não se faz necessário que alguém mostre a direção, aos poucos se pode perceber que Uma viagem à Índia, além de consistir numa peregrinação "em direção ao Oriente, em direção a Casa” (Hesse 1970: 11), dá conta de um itinerário de ida e volta ou de algumas voltas que revelam uma diferença essencial: aquele que regressa é associado ao Outro e, mais do que isso, talvez seja um "ninguém" que não tem, portanto, existência real. Vivendo como um pária, Bloom

\section{[...] [v]em de uma tragédia familiar:}

Mary, a sua amada, por razões não totalmente claras, havia sido assassinada por ordem do seu pai, que Bloom sempre admirara, mas que logo matara em vingança. Sem amor e com sangue paterno nas mãos Bloom havia decidido fazer uma viagem à Índia $\left(V I^{1}, \mathrm{~V}, 86\right)$.

A sua caracterização pode provocar no leitor o questionamento sobre a realidade e a validade de sua existência. Os destinos do pária do século XIX, que tem sua existência reduzida à insignificância, e do "nosso herói" (VI, V, 86) parricida ironicamente tipificado são o mesmo: o método da fuga. Mas Bloom não é apenas um pária social.

\section{2. “Bloom era bibliófilo até em sítios surpreendentes” (VI, VIII, 58)}

Além de funcionar como uma espécie de retrato dos "fugitivos e perseguidos" (Lourenço 2010: 16) do século XXI, a concepção de pária caracteriza este homem "europeu e português" (VI, VIII, 71) que, só no canto vII, chega à Î́ndia onde espera encontrar "sabedoria/ e esquecimento" (VI, I, 10). Como K., de O castelo, Bloom "é um estranho que nunca pode ser ajustado porque não pertence quer às pessoas comuns, quer aos seus governantes” (Arendt 2016: 515), que pode lançar mão apenas da sua "nova arma", "o pensamento" (Arendt 2016: 514).

\footnotetext{
1 As referências a Uma viagem à Índia são indicadas no corpo do texto através das iniciais VI, seguidas do número
} do canto e da estrofe. 
Os "imprevistos espantosos" (VI, II, 1) que atrapalham a "vida de um pequeno cidadão" (VI, II, 2) compõem o itinerário mental (ou ficcional) de Bloom. Ainda que o seu percurso seja pontuado por lugares que existem no mapa físico, o que se lê é a "viagem interior de Bloom/ para a Índia" (VI, VI, 5), que é também a sua "aprendizagem lenta da Índia" (VI, VI, 6). De todo modo, Bloom realiza uma viagem à Índia, embora não se saiba, de fato, a que Índia: à fábula das conquistas de Alexandre? ao sonho que se converte em experiência para a Europa no século xvi? à reencontrada terra mítica? ou ao destino turístico do século xxI? Se esta "viagem no início do século xxi” (VI, I, 6) repete a aproximação camoniana à Índia, de saber feito só de experiência, esta experiência hoje assegurada pelos "espaços turistificados" (Guerreiro 2017) não é apenas uma busca pelo país dos arquétipos. Se o "ponto de partida influencia sempre, como se sabe,/ o sítio aonde se exige chegar" (VI, II, 24), talvez sejam mais importantes, neste caso, os motivos que justificam a tentativa de fuga da realidade. Por isso, para partir, Bloom já não precisa de sair. O lugar da utopia já não é um lugar estático que exige meios de transporte para atravessar tormentas. Do mesmo modo, o que Bloom encontra em qualquer lugar não é o lá que suscita tanto o horror quanto o ideal. Nenhum outro lugar será tão infamiliar ${ }^{2}$ quanto aqui. Se não há lugar Heimlich, se nem o "ponto de partida” está isento de "hostilidade", talvez seja porque "[e]m todo o mundo o mundo é mundo" (VI, IX, 15):

É assim (e só isto interessa): por vezes o Destino de um

[homem

não chega a tempo;

esse homem arrancou já para outro local

e o ponto de partida influencia sempre, como se sabe,

o sítio aonde se exige chegar.

De certa maneira, esta é a situação de Bloom.

Um pouco confusa, enfim; não está onde o seu destino queria.

(VI, II, 24)

A partir do conto O homem da areia, de E.T.A. Hoffmann, Sigmund Freud formulou um conceito que dá título ao ensaio Das Unheimliche. Para isso, buscou em dicionários de diversas línguas significados que se aproximam do sentido de infamiliar: estrangeiro, estranho (grego); assombrado, repulsivo (inglês); sinistro, lúgubre (francês); demoníaco, aterrador (hebraico). Cito, entretanto, o trecho de uma passagem do dicionário alemão que Freud transcreveu na íntegra: "Heimlich [...] pertencente à casa, não estranho, família, domesticado, conhecido e aconchegante, caseiro etc. [...] pertencente à casa, à família, ou visto como pertencente” (Freud 2019: 37). Para Freud, infamiliar é o que provoca mal-estar, desperta terrível temor ou alude ao fantasmagórico (Freud 2019: 43). Embora não tenha encontrado como tradução a palavra hostilidade, é possível relacionar

2 Segundo os tradutores da edição de Das Unheimliche utilizada neste trabalho, "[a] dificuldade, ou até mesmo a impossibilidade, de traduzir a palavra alemã unheimlich talvez só seja comparável à dificuldade de traduzir o termo Trieb. Com maior ou menor frequência, unheimlich foi traduzido por termos como 'estranho', 'sinistro', 'inquietante', 'ominoso' ou ainda por locuções como 'inquietante estranheza,' 'estranheza familiar' ou até mesmo 'inquietante estranheza familiar'. Conforme explicitado no texto de apresentação deste volume, optamos por traduzir unheimlich por 'infamiliar'. Na presente tradução, reservamos o termo 'estranho', em português, para o que Freud designa com fremd, ou seja, o alheio, da ordem da alteridade. Com 'infamiliar' logramos manter a morfologia o mais próximo possível do original alemão” (cf. Freud 2019: 117). 
(Un)heimliche a tudo o que é hostil, uma vez que a este termo também se refere a "hostilidade que Bloom,/ o nosso herói,/ revelou em relação ao passado" (VI, I, 10):

O passado, agradável ou sombrio, sempre é um território seguro, quando menos porque já é conhecido; e a capacidade da espécie humana de reverter, de retroceder - principalmente em sonhos ou pensamentos, visto que neles geralmente estamos a salvo também - é extremamente forte em todos nós, qualquer que seja a realidade que estejamos enfrentando. No entanto, esse mecanismo foi instalado dentro de nós não para acalentarmos ou recuperarmos o passado (ao final, não fazemos nem um, nem outro), mas para adiarmos a chegada do presente - em outras palavras, para retardarmos a passagem do tempo (Brodsky 2016: 28-29).

Entretanto, também não se sabe a que passado o narrador de Uma viagem à Índia se refere: ao passado da sua "tragédia familiar", ao passado que antecede esses episódios, ao passado que remete a Leopold Bloom que remete a Ulisses, ao passado de homens que saem de casa com destino certo e vagueiam pela(s) cidade(s). Nesta viagem, que não diferencia o conhecido e o desconhecido, o "familiar se torna então infamiliar" (Freud 2019: 45). Se "[u]m homem/ que amou, matou e gosta de livros é/ um perigo errado" (VI, VIII, 58), o seu "ponto de partida" como o seu ponto de chegada como os pontos de passagem tornam-se, em geral, em sítios hostis. Bloom não conhece um lugar livre de fantasmagoria, um lugar "conhecido; amigável, confiável” (Freud 2019: 45), a não ser, talvez, em Paris. Cada lugar por onde Bloom erra é, porventura, heimlich e perigoso: "Em suma, familiar [heimlich] é uma palavra cujo significado se desenvolveu segundo uma ambivalência, até se fundir, enfim, com seu oposto, o infamiliar [unheimlich]. Infamiliar é, de certa forma, um tipo de familiar" (Freud 2019: 47-49). Com os olhos voltados para trás, este "pequeno cidadão" (VI, II, 2) está sempre envolvido com o material familiar do seu passado. Seguindo esta interpretação, o que importa aqui é a viagem interior de Bloom.

\section{3. “Não há Índia. Nem sequer o desejo de Índia.” (VI, IX, 84)}

Uma viagem à Índia é uma deambulação mental cujos cenários imaginários pressupõem uma realidade. Ainda que evoque a figura "desses Ulisses-errantes" (Arendt 2016: 490), do "pária consciente" (Arendt 2016: 491), do acossado que observa o mundo, do turista que está só de passagem, do andarilho que percorre ruas a esmo ou em fuga, embora furtivamente atento à história dos lugares, talvez Bloom não seja nada disso. A personagem que anda pelas cidades para fugir do seu passado pode ser um tipo literário, o “[ú]ltimo homem, homem da rua, homem de multidões, homem de massa, homem-massa, foi assim que apresentamos Bloom pela primeira vez: como o triste produto dos tempos das multidões, como o filho catastrófico da era industrial e do fim de todos os encantamentos"3. Neste sentido, Bloom é uma "existência espectral", "é o homem sem

3 A tradução livre é de minha responsabilidade. Cf. Tiqqun (2000: 16-17): “Dernier homme, homme de la rue, homme des foules, homme de masse, homme-masse, c'est ainsi que l'ON nous avait d'abord représenté le Bloom: comme le triste produit du temps des multitudes, comme le fils catastrophique de l'ère industrielle et de la fin de tous les enchantements". Ver também Jean-Baptiste Marongiu, La dernière surprise-partie. Un manifeste philosophique post-situationniste sur le "Bloom", personnage à peine conceptuel, "fils catastrophique de l'ère industrielle et de la fin de tous les enchantements". 
qualidades, sem substancialidade de mundo, onde já nem sequer o biopoder pega. O homem como homem, o anti-herói presente na literatura do século passado, de Kafka à [sic] Musil" (Pelbart 2007: 65). Nem herói, nem anti-herói, Bloom pode ser, ainda, um estranho na multidão cuja existência agita-se com a ilusão de que o deslocamento, ainda que mental, pode afastá-lo do luto, do real, do nada: a única coisa "que preocupa é não [existir] saída" (VI, V, 38).

Mas "Bloom, no fundo, é apenas um ser humano" ( $V I, \mathrm{~V}, 36)$ que busca, sem sossego, “[u]m Oriente ao oriente do Oriente" e, levando uma "vida de bordo", muito pessoanamente conclui: "Eu acho que não vale a pena ter/ Ido ao Oriente e visto a Índia e a China./ A terra é semelhante e pequenina/ E há só uma maneira de viver” (Pessoa 2013: 59-65). Bloom parece concordar, senão repetir, com Álvaro de Campos: "Da Índia não trago a imortalidade/ (o que me fará falta, sem dúvida), trago, sim,/ maus-tratos físicos e a perda definitiva das ilusões” (VI, IX, 14). Há, entretanto, outras coincidências entre Uma viagem à Índia e "Opiário": "Ando expiando um crime numa mala,/ Que um avô meu cometeu por requinte” (Pessoa 2013: 59-65).

\section{4. "Sem amor e com sangue paterno nas mãos Bloom havia decidido fazer uma viagem à Índia” (VI, V, 86)}

Neste contexto, o nome inglês de Bloom, que vem do "avô John John Bloom" (VI, III, 31), distancia a identificação com a realidade portuguesa ${ }^{4}$. De fato, é curioso que o protagonista desta epopeia portuguesa contemporânea, que reflete, em muitos aspectos, a obra camoniana, tenha um nome inglês e, portanto, estrangeiro. Não sei se sempre podemos confiar naquilo que um autor afirma em entrevistas. Prefiro preservar aquilo que a ficção é verdadeiramente capaz de oferecer. De todo modo, poderia pensar o nome na língua do outro, o que reanima a hipótese de a investigação literária de Gonçalo M. Tavares estar para além de questões circunscritas ao tema "escrever Portugal no século xxi”, ou pelo menos querer dar conta daquilo que é próprio da natureza humana e do amor, já que tudo neste itinerário decorre da "única velharia que chegou intacta/

Disponível em http://next.liberation.fr/livres/2000/05/04/la-derniere-surprise-partie-un-manifeste-philosophique-postsituationn iste-sur-le-bloom-personnage-a_324760.

4 Em entrevista sobre os "livros pretos", mais especificamente a propósito de A máquina de Joseph Walser, o autor justifica a escolha por nomes que evocam a cultura anglo-saxônica: "São nomes do centro da Europa, alguns alemães, mas alguns não exatamente alemães, alguns nem sequer são propriamente nomes de nenhuma nacionalidade [...]. Mas geralmente tem esse tom da Europa, germânico. É muito difícil justificar... tanto o nome das personagens como o dos livros. [...] E os nomes das personagens também às vezes não têm [sic] uma racionalidade muito concreta. O que aconteceu foi que, à medida que fui escrevendo, naturalmente senti a necessidade desse tipo de nomes. E também o que eu a posteriori percebi é que o fato de ter esses nomes afastados do meu cotidiano - não ter um Antônio, um José, uma Maria -, o fato de ter nomes que estão distantes de mim no espaço e no tempo faz com que eu olhe para essas personagens de uma forma distante e não queira defendê-las afetivamente. Tento olhar para elas como um cientista olharia para partículas químicas, ver como elas se comportariam sem participar. Não quero como narrador participar, tomar partido. É algo que acho importante, não julgar as personagens, não dizer 'essa personagem é terrível', deixar que o julgamento seja feito pelo leitor". Cf. http://m.folha.uol.com.br/ilustrada/2010/07/767901-portugues-goncalo-m-tavares-fala-sobre-maldade-saramago-eo-brasil.shtml. Ver também Vaz-Pinto 2010: 33: "Portugal não existe na literatura de Gonçalo Tavares. Nem Portugal nem portugueses. Os nomes dos personagens - Mylia, Ernest, Hanna, Theodor, Joseph Walser, Klaus Klump, Margha, Catharina, Klober, Fluzst, entre outros - [sic] contribuem para impedir a identificação com a realidade portuguesa, confirmando a distância desta literatura de questões como identidade. Este aspecto, por si só, desperta a curiosidade sobre este escritor em meio a uma literatura onde é comum pensar a subjetividade relacionada com problemas da identidade". 
ao estúpido século xxI" (VI, IX, 32). E isso, provavelmente, não faz de Bloom um infamiliar. Ou talvez contribua de alguma forma para esta leitura, já que “'Amor é saudade do lar [Heimweh]', afirma um gracejo, e se o sonhador ainda no sonho pensa num lugar ou numa paisagem: isso me é conhecido [...]. O infamiliar é, então, também nesse caso, o que uma vez foi doméstico, o que há muito é familiar" (Freud 2019: 95).

\title{
5. “as viagens, por exemplo, e aquela em particular, são um pouco de morte quando se chega, e um pouco ainda de morte quando de um sítio se parte" (VI, X, 80)
}

O modo como o mundo é figurado em Uma viagem à Índia não só é coerente com a realidade contemporânea como reflete diversas circunstâncias que a abrangem, embora muito daquilo que poderia ser infamiliar no real não parece ser na narrativa:

\begin{abstract}
A coisa é diferente, entretanto, quando o escritor se coloca, aparentemente, no interior da realidade comum. Nesse caso, ele assume também todas as condições que são válidas, nas vivências, para o surgimento do infamiliar, e tudo aquilo que, na vida, tem efeito infamiliar também o tem na criação literária. Mas, nesse caso, o escritor pode elevar e diversificar esse infamiliar bem além daquilo que é possível nas vivências, na medida em que ele deixa acontecer aquilo que, na realidade, raramente ou nunca chega a se tornar experiência. Em certa medida, ele trai as crenças que supúnhamos superadas, ele nos ilude, na medida em que nos promete a realidade comum, quando, de fato, vai muito além dela (Freud 2019: 109-111).
\end{abstract}

Bloom vai muito além da realidade comum, porque Bloom percebe que "[e]ntre Proust e o «Bhagavad-Ghitá»/ talvez até existam diferenças mais significativas/ que entre Paris e Calcutá" (VI, IV, 79), o seu discurso tem mais valor que o seu percurso de regresso "ao sítio de onde parti[u], Lisboa" (VI, X, 143). Com uma mala pequena na mão e "uma edição antiga do livro mítico «Mahabarata»/ roubada a um mestre perverso" (VI, X, 144), um rádio de bolso que não funciona - "o velho rádio do pai nem/ com a viagem voltou a funcionar" (VI, X, 156) -, uma mulher assassinada a quem Bloom continua amando e "[u]m cadáver [] encontrado no lago de um parque" (VI, X, 132) - "a polícia procura-[o] por dois assassinatos/ - um aqui e outro em Paris,/ e a [] mãe morreu há meses. Não deixou cartas, nem herança” (VI, X, 147) - na volta da viagem à Índia, "Lisboa recebe Bloom sem comoção. As cidades/ perderam a capacidade para admirar as grandes viagens./ Bloom olha de longe para a casa onde foi feliz; e nada sente." (VI, X, 148). Talvez "a casa da infância" esteja mesmo "fechada" (VI, X, 130). Quando "[c]hega a Lisboa", "[n]enhum ódio o recebe e nenhum amor" (VI, X, 145). 


\section{6. “Qualquer biografia é assim: avança-se para o sítio de onde se partiu" (VI, X, 130)}

Embora o título anuncie que se trata de uma viagem à Índia, o livro nem sempre parece ter percorrido os países que descreve. Utilizando os meios de transporte à disposição do viajante do século XXI, este itinerário acaba também por "penetra[r] no terreno da grandiosidade e da magia" (Hesse 1970: 5). Se esta viagem à Índia é mesmo uma peregrinação "em direção ao Oriente, em direção a Casa” (Hesse 1970: 11), ao retomar cenários e personagens (e textos) da história da humanidade, pode-se refletir que

a velha questão do exílio não é mais o que costumava ser. Não é mais sair de Roma civilizada e ir para a Sarmácia inculta, não é mandar um homem da Bulgária, digamos, para a China. Não; como regra, o que acontece é uma transferência de um lugar atrasado para uma sociedade industrialmente avançada, com a última palavra sobre a liberdade individual. E cabe acrescentar que, para um escritor exilado [ou para um leitor, no caso de Bloom], tomar esse caminho equivale em muitos aspectos a voltar para casa (Brodsky 2016: 18-19).

Aqui, no entanto, não é bem assim, ainda que Bloom se torne "uma agulha naquele famoso palheiro - mas uma agulha que é procurada por alguém: é disso que se trata quando falamos em exílio" (Brodsky 2016: 21).

\section{7. “procuro uma mulher porque quero esquecer outra” (VI, III, 124)}

Nesta circunstância, quero citar três passagens do Livro do Desassossego que refletem "Índias impossíveis" (Pessoa 2006: 90):

1. "O meu desejo é fugir. Fugir ao que conheço, fugir ao que é meu, fugir ao que amo. Desejo partir - não para as Índias impossíveis [...], mas para o lugar qualquer - aldeia ou ermo - que tenha em si o não ser este lugar" (Pessoa 2006: 182).

2. "Poderei ir buscar riqueza ao Oriente, mas não riqueza de alma, porque a riqueza da minha alma sou eu, e eu estou onde estou, sem Oriente ou com ele" (Pessoa 2006: 144).

3. "Escrevo atentamente, curvado sobre o livro em que faço a lançamentos a história inútil de uma firma obscura; e ao mesmo tempo o meu pensamento segue, com igual atenção, a rota de um navio inexistente por paisagens de um oriente que não há” (Pessoa 2006: 291).

Busco, nas vinte páginas que seguem Uma viagem à Índia, que tem por subtítulo Melancolia contemporânea (um itinerário), palavras e conceitos que remetem ao sentido dos termos referidos, sem acreditar, contudo, que se possa encontrar em cada estância os motivos correspondentes. Diante deste itinerário, espécie de mapa de palavras, talvez esteja mais perto de pistas falsas que de uma lista que relacione diretamente conceitos e estâncias. Com esse mapa nas mãos, não tenho a certeza se, de fato, "o ponto de partida influencia sempre, como se sabe,/ o sítio aonde se exige chegar" (VI, II, 24). Talvez esteja, mais acertadamente, diante de marcas do itinerário 
de Bloom, que foge aparentemente de um homicídio, mas, na realidade, esta "viagem no início do século xxi" (VI, I, 6) é uma narrativa com outras camadas de possíveis significações. Se a viagem à Índia "inaugur[a] um tempo para sempre fora do tempo" (Lourenço 2013: 7), para esse deslocamento, “[a] Índia tornou-se um destino claro/ [...], mas percebi de imediato/ que não poderia demorar apenas horas/ a saltar de um mundo para outro" (VI, IV, 80). Encontrei a estância 80 do canto IV ao me deparar, no "mapa", com a palavra "fuga" que correspondia à estância seguinte, 81 :

$$
\begin{aligned}
& \text { Depois do assassinato que cometi } \\
& \text { fui ajudado por dois amigos } \\
& \text { que me queriam acompanhar na fuga. } \\
& \text { Mas deve-se sempre fugir sozinho, eis } \\
& \text { o que aprende desde cedo um homem } \\
& \text { que goste de livros. }
\end{aligned}
$$

$(V I, I V, 81)$

Ajudaram-me os amigos - continuou Bloom -,

primeiro a apagar os vestígios do crime,

depois a preparar a viagem, uma viagem que parecesse

[inocente:

alguém que parte para esquecer

e não para esquecer e não ser incriminado.

Assim, graças às várias ajudas,

consegui sair de Lisboa como alguém que sofreu duas vezes

e nenhuma vez fez sofrer.

$(V I, I V, 82)$

Estas estâncias destacadas em sequência favorecem a compreensão do itinerário circular percorrido por Bloom, na medida em que, de certo modo, revisitam a "desejada parte Oriental" a partir da leitura da estância 69 do canto v na epopeia camoniana. Neste contexto, ir à Índia no século Xxi reflete sobre as relações da Europa com o Oriente por ela inventado, cujas construções míticas foram refeitas e revistas quantas vezes se tentou assegurar os sentidos do Oriente, produzindo um "conhecimento distorcido do outro" (Said 2007: 19), seja pela romantização de um cenário, seja pela demonização de um inimigo. Pelo itinerário de Bloom, pode-se desconstruir esse conhecimento e compreender, novamente, que "[e]m todo o mundo o mundo é mundo" (VI, IX, 15). Bloom parece não ter encontrado no Oriente aquilo que buscava. Bloom é "um outro", é um eu que é outro (Rimbaud) - "deixe-me falar de mim como se eu fosse um outro" (VI, III, 119) -, "europeu e português" (VI, VIII, 71), português e estrangeiro em relação ao outro e em relação a si mesmo, que carrega "esse desnorteamento da distância que nos mantém completamente afastados” (Blanchot 2011: 93). Este outro, cuja experiência individual também evoca Walt Whitman ${ }^{5}$,

$5 \quad$ Walt Whitman. "Eu Canto Um Eu":

Eu canto um eu, uma pessoa simples separada,

Porém profiro a palavra Democrático, a palavra En-Masse. 
permite reconfigurar algumas imagens oníricas já anunciadas desde a estrofe 69 do canto v d'Os Lusíadas:

Desta gente refresco algum tomámos

E do rio fresca água; mas contudo

Nenhum sinal aqui da Índia achámos

No povo, com nós outros casi mudo.

Ora vê, Rei, quamanha terra andámos,

Sem sair nunca deste povo rudo,

Sem vermos nunca nova nem sinal

Da desejada parte Oriental.

O sujeito, implícito nessa estrofe, deseja alcançar o inalcançável objeto de desejo, em ambas as obras metaforizado através deste "sítio aonde se exige chegar" (VI, II, 24), não mais orientalizado nos aspectos que se tornaram lugares-comuns para um europeu do século XIX, nem na relação hegemonicamente complexa de dominação e poder pelo Ocidente. Bloom pretende "percorrer o caminho mais lento" (VI, IV, 80).

\section{8. “Quantos quilómetros serão necessários percorrer até que um homem esqueça algo?" (VI, IV, 100)}

Refutando as expectativas de Bloom, que "procurará o impossível:/ encontrar a sabedoria enquanto foge; / fugir enquanto aprende” (VI, I, 39), a sua viagem à Índia, como descobre mais tarde, acaba por não corresponder à "Proposição" que havia estabelecido. Com efeito, nesse desencontro com a Índia sonhada, Bloom descobre, como refere Eduardo Lourenço, “que os seus «gurus» são vulgares e suspeitos vendedores de ilusões como todos os outros" (2010: 16). Recordo, a este propósito, "uma forma de pensamento para lidar com o estrangeiro" (2007: 80) amplamente estudada por Edward Said: "O Orientalismo constituía em última análise uma visão política da realidade, cuja estrutura promovia a diferença entre o familiar (a Europa, o Ocidente, 'nós') e o estranho (o Oriente, o Leste, 'eles')" (Said 2007: 78). Mas o estranho é tanto o Unheimliche freudiano quanto o desassossego pessoano materializado neste outro lado, quer seja o Oriente, quer seja o passado, inevitavelmente inalcançável, inevitavelmente outro. Assim como Ulisses, “[c]ertamente ele arrasta seu público a um mítico mundo de sonho, mas esse mundo de sonho se torna simultaneamente a imagem especular do mundo real em que vivemos, no qual dominam necessidades e angústia, terror e dores, e no qual o homem se acha imerso sem escapatória" (Calvino 1993:

Fisiologia dos pés à cabeça canto,

Não só fisionomia nem só cérebro é digno da Musa,

Digo que a Forma completa é muito mais digna,

A Feminina igualmente com a Masculina canto.

Da Vida imensa em paixão, pulso e poder,

Jovial, formado para a ação mais livre sob as leis divinas,

O Homem Moderno canto. 
23-24). Paralelamente a isso, o narrador de Uma viagem à Índia se dá conta de que "cada um é inseparável da sua maldade": "[d]e facto, Bloom já o sabe há muito:/ somos inseparáveis do nosso pior” (VI, VIII, 84). E porque uma das coisas que procura é a sabedoria, Bloom, já na Índia, é apresentado a um sábio. Cada um estrangeiro em relação ao outro, Bloom encontra Shankra, "sábio" cuja

\section{[...] fachada sábia revela, então, pouco a pouco}

o que esconde.

Bloom está na verdade diante de um ladrão.

De livros, muito bem, mas ladrão

(VI, VIII, 83).

Bloom realiza uma viagem que já não é, portanto, à "desejada parte Oriental” (Lus., V, 69). Mas insistir na viagem rumo àquela Índia sonhada que continuamos "[s]em ver[] nunca nova nem sinal" pode ser uma forma de "[s]obreviver[] à maldade que a natureza/ por vezes tem,/ e sobreviver[] à maldade que os homens,/ por hábito, praticam” (VI, VI, 94). O sentido da viagem de Bloom não é guiado apenas por uma busca expressa na sua "Proposição", é também um refúgio que se estende no próprio movimento de fugir. Como se Bloom se perdesse para se conhecer, é a sua própria existência desassossegada que justifica a fuga deste homem que matou o próprio pai que, por sua vez, havia assassinado a sua mulher. A princípio, Bloom viaja para se afastar de casa, foge como quem foge de uma tragédia, mantendo, entretanto, uma direção. Recorrendo mais uma vez ao "mapa" que segue Uma viagem à Índia, notei que a estância 50 do canto x é indicada pelas palavras "Ocidente/Oriente”. Li imediatamente esta estância e vi que o encontro com Shankra não proporcionou a Bloom a sabedoria que imaginava alcançar, mas o fez perceber que "o uso da língua pemitiu que o familiar deslizasse para seu oposto, o infamiliar, uma vez que esse infamiliar nada tem realmente de novo ou de estranho, mas é algo íntimo à vida anímica desde muito tempo" (Freud 2019: 85):

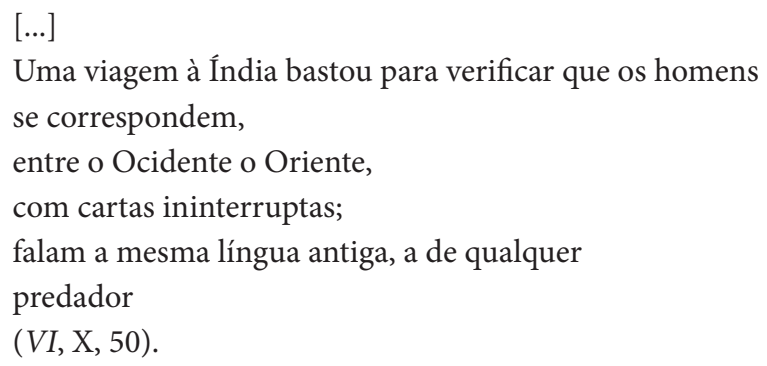

Apesar de estar em movimento, Bloom também está, de certo modo, paralisado pelas mortes que sofreu e cometeu. Recordo que "Mary, a sua amada, por razões não totalmente claras,/ havia sido assassinada por ordem do pai,/ que Bloom sempre admirara, mas que logo matara em/ vingança" (VI, V, 86). À procura de “[u]m tédio surpreendente" (VI, I, 64), Bloom parece, a cada passo, querer caminhar para fora da vida, possibilidade que se anuncia, afinal, nas últimas estâncias do livro. Bloom vive numa espécie de exílio e, para ele, só há uma redenção possível: "uma mulher ou algo que me faça deixar/ de a procurar. Não sei se me entende./ A sabedoria, enfim. E chegar à 
Índia” (VI, II, 79). Embora “[p]rocur[e] uma mulher [...] ou então/ a sabedoria” (VI, II, 70), talvez o que Bloom mais deseje esquecer seja "a morte misturada com o amor/ numa mistura estúpida" $(V I, \mathrm{~V}, 87)$ para (re)encontrar o amor universal, embora "até o amor" tenha ficado "pálido/ depois de certos povos maltratarem, de modo organizado,/ conjuntos de pessoas/ que falavam outra língua e lembravam outro passado" (VI, III, 117).

\section{9. "O futuro e o passado têm agora a mesma substância, nada mudou. Valeu pois a pena viajar, pensa. Pelo menos percebi que nada adianta" (VI, X, 78)}

Bloom regressa ao ponto de partida, mas "Lisboa recebe Bloom sem comoção" (VI, X, 148). A personagem que regressa de comboio a Lisboa talvez não seja mais a mesma que partiu para a Índia. Ao contrário do Ulisses homérico, que pretende, a todo custo, recuperar seu passado, a "aprendizagem lenta da Índia" (VI, VI, 6) para Bloom começa como uma "viagem interior", uma evasão marcada pela impossibilidade de recuperar o passado anterior à morte de Mary e, portanto, de restaurar uma ordem ideal. Bloom "[p]rocurou o Espírito" (VI, X, 149) num "país tão espiritual” (VI, IV, 88) e "encontrou a matéria que já conhecia" (VI, X, 149): "Bloom sonhava que na Índia/ pudesse ser diferente" (VI, IV, 76), mas conclui que "[a] vida é isto":
[...] Querendo fugir de sofrimentos
do passado, e pensando encontrar na Índia a crença
e os homens luminosos que na Europa da ciência não
encontrara, eis que chega a isto: é terça-feira
num continente gigante, e Bloom está numa cova escura
e apertada, curvado sobre si mesmo como um lobo
que tem medo.
(VI, IX, 10)

De regresso a Lisboa, perdido por ruas familiares, surge uma solução tão clara e violenta quanto "a suprema e melhor garantia de liberdade humana” (Arendt 2016: 483): “[h]á várias maneiras de um corpo se matar,/ e cair do alto sobre a água é uma delas” (VI, X, 155). No alto duma ponte, entretanto, um último encontro suspende a tentativa de suicídio quando uma "mulher bonita" se aproxima e sorri (VI, X, 155): "Não quer conversar?, pergunta ela”. Mas "Bloom encolhe os/ ombros." "Ele aproxima-se da mulher", não sabemos se para matar ou conversar, "e o mundo prossegue" (VI, X, 156). E fica parecendo até que “[o] amor não existe” (VI, X, 130) ou que "[o] amor existe,/ mas não num ser vivo que se move” (VI, IX, 89). Assim como boa parte da lírica camoniana, todo o texto de Gonçalo M. Tavares é uma jornada em busca de sentido para as contradições daquilo que no amor é humano. Sempre o mesmo e sempre outro, todos e cada um, atual e antigo na civilização ocidental contemporânea, Bloom continua a se achar incerto ${ }^{6}$ porque "unilateral", já que "o seu único lado/ era este: o lado virado para Mary” (VI, III, 119). 


\section{Referências bibliográficas}

Arendt, H. (2016). Escritos Judaicos. São Paulo: Amarilys.

Blanchot, M. (2011). Uma voz vinda de outro lugar. Rio de Janeiro: Rocco.

Brodsky, J. (2016). Sobre o exílio. Belo Horizonte: Editora Âyiné.

Calvino, I. (1993). As Odisseias na Odisseia. In Por que ler os clássicos? (pp. 17-24). São Paulo: Companhia das Letras.

Camões, L. (1978). Os Lusíadas. Ed. E. P. Ramos. Porto: Porto Editora.

Freud, S. (2019). O infamiliar/ Das Unheimliche seguido de O Homem da Areia, de E.T.A. Hoffmann. Ed. Bilingue. Belo Horizonte: Autêntica Editora.

Guerreiro, A. (2017). O turismo total. Ípsilon, Público. <https://www.publico.pt/2017/06/16/culturaipsilon/ opiniao/o-turismo-total-1775561>

Hesse, H. (2001). Die Morgenlandfahrt. Frankfurt am Main: Suhrkamp Verlag.

- (1970). Viagem ao Oriente. Rio de Janeiro: Civilização Brasileira.

Lourenço, E. (2010). Uma viagem no coração do caos. In G. M. Tavares (Ed.), Uma Viagem à Índia: Melancolia contemporânea (um itineráio) (pp. 5-16). São Paulo: Leya.

. (2013). A Dupla Viagem. In A. Faria (Ed.), O murmúrio do mundo: a Índia revisitada (pp. 7-16).

Rio de Janeiro: Tinta-da-china Brasil.

Marongiu, J.-B. (2000). La dernière surprise-partie. Un manifeste philosophique post-situationniste sur le «Bloom», personnage à peine conceptuel, «fils catastrophique de l'ère industrielle et de la fin de tous les enchantements». Tiqqun. La Théorie du Bloom. La Fabrique éditions, 140pp., 59f. Libération, Critique. <http://next.liberation.fr/livres/2000/05/04/la-derniere-surprise-partie-un-manifeste-philosophique-post-situationniste-sur-le-bloom-personnage-a_324760>

Pelbart, P. P. (2007). Biopolítica. Sala Preta, 7, 57-65.

Pessoa, F. (2006). Livro do Desassossego. Org. R. Zenith. São Paulo: Companhia das Letras. . (2013). Poesia de Álvaro de Campos. Lisboa: Assírio \& Alvim.

Said, E. (2007). Orientalismo: o Oriente como invenção do Ocidente. São Paulo: Companhia das Letras.

Tavares, G. M. (2010). Uma viagem à Índia: Melancolia contemporânea (um itinerário). Pref. E. Lourenço. São Paulo: Leya.

Tiqqun (2000). Théorie du Bloom. Paris: La Fabrique éditions.

Vaz-Pinto, M. (2010). Gonçalo Tavares: o filho mais desenvolto de Álvaro de Campos? Convocação de textos.

Abril, 4, 31-39. 